\title{
Presence of HIF-1 and related genes in normal mucosa, adenomas and carcinomas of the colorectum
}

\author{
Astrid E. Greijer • Pien M. Delis-van Diemen • \\ Remond J. A. Fijneman • Rachel H. Giles • \\ Emile E. Voest • Victor W. M. van Hinsbergh • \\ Gerrit A. Meijer
}

Received: 5 November 2007 /Revised: 7 January 2008 / Accepted: 7 January 2008 / Published online: 20 March 2008

(C) The Author(s) 2008

\begin{abstract}
Expression of the transcription factor hypoxiainducible factor 1 (HIF-1), which plays a key role in cellular adaptation to hypoxia, was investigated in normal colorectal mucosa (ten), adenomas (61), and carcinomas (23). Tissue samples were analyzed for HIF-1 $\alpha$, its upstream regulators, von Hippel-Lindau factor, AKT, and mammalian target of rapamycin (mTOR) and its downstream targets glucose transporter 1 (GLUT1), carbonic anhydrase IX, stromal-cell-derived factor 1 (SDF-1) by immunohistochemistry. In normal colorectal mucosa, HIF$1 \alpha$ was observed in almost all nuclei of surface epithelial cells, probably secondary to a gradient of oxygenation, as indicated by pimonidazole staining. The same staining pattern was present in $87 \%$ of adenomas. In carcinomas, HIF- $1 \alpha$ was present predominantly around areas of necrosis
\end{abstract}

Part of this work was financially supported by the 1st AEGON International Scholarship in Oncology (AEG, PMDvD, RJAF).

A. E. Greijer · P. M. Delis-van Diemen - R. J. A. Fijneman • G. A. Meijer $(\bowtie)$

Department of Pathology, VU University Medical Centre, PO Box 7057, 1007 MB Amsterdam, The Netherlands

e-mail: ga.meijer@vumc.nl

A. E. Greijer · P. M. Delis-van Diemen - R. J. A. Fijneman Department of Medical Oncology, VU University Medical Center, Amsterdam, The Netherlands

V. W. M. van Hinsbergh

Department of Physiology, VU University Medical Center,

Amsterdam, The Netherlands

R. H. Giles • E. E. Voest

Department of Medical Oncology,

University Medical Center Utrecht,

Utrecht, The Netherlands
(78\%). Active AKT and mTOR, were present in all adenomas, carcinomas, and in normal colorectal mucosa. GLUT1 and SDF-1 were present in the normal surface epithelium of all adenoma cases, whereas in the carcinoma GLUT1 was located around necrotic regions and SDF-1 was present in all epithelial cells. In conclusion, HIF-1 $\alpha$ appears to be physiologically expressed in the upper part of the colorectal mucosa. The present observations support that upregulation of HIF- $1 \alpha$ and its downstream targets GLUT1 and SDF-1 in colorectal adenomas and carcinomas may be due to hypoxia, in close interaction with an active phosphatidylinositol 3-kinases-AKT-mTOR pathway.

Keywords HIF- $1 \cdot$ mTOR $\cdot \mathrm{SDF}-1 \cdot \mathrm{CA}$ IX $\cdot$ Colon

\section{Introduction}

Colorectal carcinomas arise from normal epithelial cells of the colorectal mucosa through an adenoma stage. The transition from benign adenomas to malignant carcinomas, occurring in about $5 \%$ of all adenomas, is only beginning to be explored in appreciable detail. Biological changes involved in this process include important signaling pathways like the mammalian target of rapamycin (mTOR) AKT pathway while recently also a role for hypoxia-driven signaling was shown $[6,14]$. Both pathways are mediated by the transcription factor hypoxia-inducible factor 1 (HIF1) as depicted in Fig. 1. HIF-1 is involved in cellular adaptation to hypoxia in solid tumors, including stimulation of angiogenesis and glycolysis [33]. HIF-1 consists of two subunits of which the $\beta$-subunit is constitutively expressed, whereas HIF- $1 \alpha$ is regulated in particular by the oxygen level. Under normoxia, the HIF- $1 \alpha$ protein is hydroxylated by prolyl hydroxylases $[15,16]$, which enables the von 


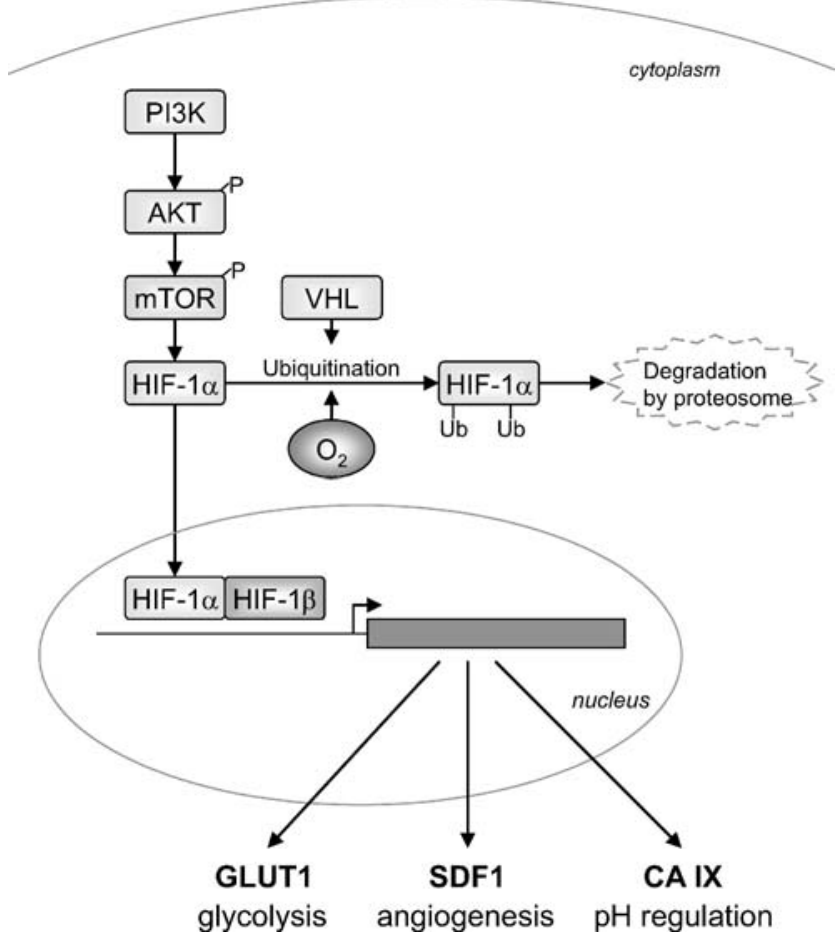

Fig. 1 Schematic representation of the interaction of the analyzed proteins. The PI3K-AKT-mTOR pathway is inducing HIF-1 $\alpha$. In addition, the absence of hypoxia prevents HIF- $1 \alpha$ from degradation mediated by VHL. When HIF- $1 \alpha$ is present, it binds to HIF- $1 \beta$ in the nucleus. The formed complex activates target genes, like GLUT1, SDF1, and CA IX

Hippel-Lindau factor (VHL) to bind, resulting in ubiquination and rapid degradation by the proteosome [27]. HIF$1 \alpha$ is overexpressed in many solid tumors [38] and its presence has been correlated with, i.e., poor prognosis in breast and colorectal cancer patients [4, 36]. Stromal expression of hypoxia-regulated proteins is an adverse prognostic factor in colorectal carcinomas.

High protein levels of HIF- $1 \alpha$ are not only caused by hypoxia but can also be induced by the absence of wildtype protein 53, mutated VHL and other tumor suppressor genes, as well as by activation of oncogenes like Her2neu (c-erbB-2) [24]. In addition, growth factors play a role. However, both hypoxia and signaling-mediated HIF-1 stimulation are mediated by the phosphatidylinositol 3kinase (PI3K)-AKT, and the mTOR pathway [8]. Interestingly, both the serine-threonine protein kinase AKT as well as mTOR have been suggested to play a role in an early stage of colorectal carcinogenesis [2, 30]. Furthermore, the presence of a non-hypoxic HIF-1 induction has also been suggested, in colorectal adenomas [9].

Upon HIF-1 activation, multiple target genes become transcriptionally active, including genes involved in anaerobic glycolysis, metabolism, and angiogenesis. This includes glucose transporter 1 (GLUT1), which facilitates cellular glucose uptake $[11,26]$ and the angiogenesis- associated genes vascular endothelial growth factor and stromal-cell-derived factor 1 (SDF-1) also known as CXCL12 [5]. Furthermore, carbonic anhydrase IX (CA IX) which is prominently induced by hypoxia and is therefore considered to be an intrinsic hypoxia marker, which correlates with a chemical marker of hypoxia, pimonidazole [1, 17, 23, 28]. An additional function of CA IX is in the regulation of the maintenance of the physiological equilibrium in normal gastrointestinal tissue [31].

The present study aims to analyze the role HIF-1 in normal colorectal mucosa, adenomas, and carcinomas. To this end, the presence of HIF-1 $\alpha$ as well as of its downstream targets GLUT1, SDF-1, and CA IX were analyzed in normal colon tissue, colorectal adenomas, and carcinomas. To explore the possible cause of HIF-1 overexpression, i.e., hypoxia or oncogenic stimulation, both the presence of the chemical hypoxia marker pimonidazole and of the HIF- $1 \alpha$ upstream regulators, VHL, AKT, and mTOR, were investigated.

\section{Materials and methods}

\section{Tumor material}

A total of 84 tissue samples were studied, consisting of 61 colorectal adenomas, 20 of which contained already a focus of carcinoma and are therefore referred to as progressed adenomas, in contrast to the 41 adenomas with dysplasia only, which are referred to as nonprogressed adenomas. In addition, 23 colorectal carcinomas were analyzed. These samples were obtained from 75 patients, 37 of which were female and 38 male. Mean age was 67.8 years (range 40 89). Normal mucosa samples were obtained from the resection margins of colectomy specimens from ten patients with colorectal cancer. The study was approved by the Institutional Review Board and was in accordance with Dutch medical ethical guidelines.

\section{Determination of hypoxic regions}

Hypoxic regions in mouse tissues were visualized using the Hydroxyprobe-1 kit (Chemicon International, Temecula, CA, USA). These experiments were approved by the animal experimentation ethics committee, according to local and governmental regulations.

Briefly, mice were injected intravenously with pimonidazole $(60-\mathrm{mg} / \mathrm{kg}$ body weight), which forms adducts from reductively activated pimonidazole in hypoxic cells. Mice were killed 90 min later by asphyxiation in $\mathrm{CO}_{2}$. The Hydroxyprobe-1 monoclonal antibody was biotinylated using D-biotinyl- $\varepsilon$-aminocaproic acid $N$-hydroxysuccinimide ester (Boehringer Mannheim) and was used to stain 
pimonidazole adducts in formalin-fixed paraffin-embedded tissues according to recommendations by the manufacturer.

Immunohistochemistry

Immunohistochemistry was performed on $4-\mu m$-thick fullblock consecutive sections. Slides were deparaffinized, followed by rehydration, and subsequently staining in batches with the antibodies described in Tables 1 and 2 . HIF-1 $\alpha$ staining was performed as described previously [3]. In brief, antigen retrieval was performed in antigen retrieval solution (DAKO, Glostrup, Denmark) for $45 \mathrm{~min}$ at $96^{\circ} \mathrm{C}$. The primary antibody against HIF- $1 \alpha$ was incubated at a dilution of 1:500 for $30 \mathrm{~min}$ at room temperature and the catalyzed signal amplification system (DAKO) was used for detecting HIF- $1 \alpha$ staining.

For CA IX staining, no antigen retrieval step was used. Slides were incubated with a mouse primary antibody to CA IX in a 1:50 dilution for $30 \mathrm{~min}$ at room temperature. Detection was performed with the Envision+ systemhorseradish peroxidase system for mouse primary antibodies (DAKO).

GLUT-1 staining was performed with a rabbit polyclonal anti-GLUT1 (antibody clone A 3536, DAKO, dilution 1:400) without antigen retrieval and subsequently developed with a standard avidin-biotinylated peroxidase complex (DAKO).

Staining procedures for AKT and mTOR were identical. After antigen retrieval, endogenous peroxidase activity was blocked for $10 \mathrm{~min}$ in methanol containing $0.3 \%$ hydrogen peroxide. The AKT antibody (Phospho-Akt (Ser473)) and mTOR antibody (Phospho-mTOR (Ser2448)) both obtained from Cell Signaling (Danvers, MA, USA) were incubated overnight at $4^{\circ} \mathrm{C}$ in a 1:50 dilution and subsequently detected with a standard avidin-biotinylated peroxidase complex.

SDF-1 staining was performed similar to the AKT and mTOR staining, except for the secondary antibody, which was a goat anti-rabbit antibody in this case.
For VHL staining, antigen retrieval was performed and endogenous peroxidase was blocked as the AKT and mTOR staining. Primary antibody against VHL was incubated for $60 \mathrm{~min}$ by room temperature, followed by Powervision (Immunologic, Duiven, the Netherlands) incubation for $30 \mathrm{~min}$ and subsequently the staining was detected with diaminobenzidine (SIGMA FAST ${ }^{\mathrm{TM}}$ 3,3'diaminobenzidine tablets, Sigma Aldrich, St. Louis, MO, USA).

Before the slides were mounted with cover slips, all sections were counterstained for $30 \mathrm{~s}$ with Mayer's hematoxylin and dehydrated in $70 \%, 96 \%$, and subsequently $100 \%$ ethanol and finally in xylene.

Evaluation and statistics

The intensity of the staining was compared between the normal mucosa, nonprogressed, progressed adenomas, and carcinomas and scored by two investigators. Staining intensity was scored in four classes $(0$ to 3$)$ taking the negative control as a reference for score 0 and the positive control (clear cell renal adenocarcinomas (Grawitz tumor) as a reference for score 3). For HIF-1 $\alpha$, only nuclear staining was scored, for CA IX, membrane staining, and AKT and SDF-1 cytoplasmic staining, for mTOR predominantly cytoplasmic but also membrane staining was scored. Significance of differences between categories was analyzed by means of the Kruskal Wallis test. $P$-values $<0.05$ were considered to be significant.

\section{Results}

HIF- $1 \alpha$ expression and its regulators hypoxia and VHL

In normal colorectal mucosa nine out of ten samples showed HIF- $1 \alpha$ present in nuclei of the surface epithelium (Fig. 2). To evaluate whether hypoxia played a physiologic

Table 1 Details of the immunohistochemical stainings

\begin{tabular}{|c|c|c|c|c|c|c|}
\hline Antibody & Species & Company and institutes & Dilution & Incubation & Antigen retrieval & Detection \\
\hline HIF-1 $\alpha$ & Mouse & BD Pharmingen & $1 / 500$ & $30^{\prime} \mathrm{RT}$ & WB TRS $97^{\circ} \mathrm{C} 45^{\prime}$ & CSA \\
\hline Akt & Rabbit & Cell Signaling & $1 / 50$ & $\mathrm{o} / \mathrm{n} 4^{\circ} \mathrm{C}$ & WB Citr $97^{\circ} \mathrm{C} 10^{\prime}$ & $\mathrm{ABC}$ \\
\hline mTOR & Rabbit & Cell Signaling & $1 / 50$ & $\mathrm{o} / \mathrm{n} 4^{\circ} \mathrm{C}$ & WB Citr $97^{\circ} \mathrm{C} 10^{\prime}$ & $\mathrm{ABC}$ \\
\hline VHL & Mouse & BD Pharmingen & $1 / 100$ & $60^{\prime} \mathrm{RT}$ & WB Citr $97^{\circ} \mathrm{C} 20^{\prime}$ & Powervision \\
\hline CA IX & Mouse & Lab Harris & $1 / 50$ & $30^{\prime} \mathrm{RT}$ & none & Envision+ \\
\hline Glut-1 & Rabbit & DAKO & $1 / 400$ & $60^{\prime} \mathrm{RT}$ & WB Citr $97^{\circ} \mathrm{C} 20^{\prime}$ & $\mathrm{ABC}$ \\
\hline SDF-1 & Mouse & $\mathrm{R} \& \mathrm{D}$ systems & $1 / 400$ & $\mathrm{o} / \mathrm{n} 4^{\circ} \mathrm{C}$ & WB Citr $97^{\circ} \mathrm{C} 10^{\prime}$ & $\mathrm{ABC}$ \\
\hline Hydroxyprobe-1 & Mouse & Chemicon International & $1 / 200$ & $40^{\prime} \mathrm{RT}$ & $0.01 \%$ pronase in $\mathrm{PBS} 40^{\circ} \mathrm{C}$ for $40^{\prime}$ & $\mathrm{ABC}$ \\
\hline
\end{tabular}

$B D$ Transduction laboratories, Mab monoclonal antibody, $P A b$ polyclonal antibody, $R T$ room temperature, $W B$ water bath, $T R S$ target retrieval

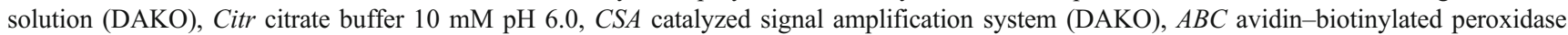
complex, Powervision from immunologic R\&D systems 
Table 2 Number (and percentages) of HIF- $1 \alpha$, P-AKT, P-mTOR, VHL, CA IX, GLUT1, and SDF-1 expression in nonprogressed and progressed colorectal adenomas and adenocarcinomas in the respective categories of staining intensity

${ }^{\mathrm{a}}$ One case not tested

\begin{tabular}{|c|c|c|c|c|c|}
\hline & & $\begin{array}{l}\text { Nonprogressed } \\
\text { Adenoma, } n=41\end{array}$ & $\begin{array}{l}\text { Progressed } \\
\text { adenoma, } n=20\end{array}$ & $\begin{array}{l}\text { Adenocarcinoma, } \\
n=23\end{array}$ & $\begin{array}{l}\text { Kruskal-Wallis } \\
\text { test, } P \text {-value }\end{array}$ \\
\hline \multirow[t]{4}{*}{ HIF-1 } & Neg & $6(15)$ & $2(10)$ & $5(22)$ & 0.8 \\
\hline & + & $0(0)$ & $2(10)$ & $1(4)$ & \\
\hline & ++ & 7 (17) & $3(15)$ & $3(13)$ & \\
\hline & +++ & $28(68)$ & $13(65)$ & $14(61)$ & \\
\hline \multirow{4}{*}{$\mathrm{AKT}$} & $\mathrm{Neg}$ & $0(0)$ & $0(0)$ & $0(0)$ & 0.1 \\
\hline & + & $12(29)$ & $7(35)$ & $0(0)$ & \\
\hline & ++ & $11(27)$ & $5(25)$ & $10(43)$ & \\
\hline & +++ & $18(78)$ & $8(40)$ & $13(57)$ & \\
\hline \multirow[t]{4}{*}{ mTOR } & $\mathrm{Neg}$ & $2(5)$ & $0(0)^{\mathrm{a}}$ & $0(0)$ & 0.4 \\
\hline & + & $2(5)$ & $3(16)$ & $0(0)$ & \\
\hline & ++ & $12(29)$ & $6(32)$ & $7(30)$ & \\
\hline & +++ & $25(61)$ & $10(53)$ & $16(70)$ & \\
\hline \multirow[t]{4}{*}{ VHL } & $\mathrm{Neg}$ & $0(0)^{\mathrm{a}}$ & $1(5)$ & $0(0)$ & 0.9 \\
\hline & + & 7 (18) & $0(0)$ & $1(4)$ & \\
\hline & ++ & $12(30)$ & $11(55)$ & $11(48)$ & \\
\hline & +++ & $21(53)$ & $8(40)$ & $11(48)$ & \\
\hline \multirow[t]{4}{*}{ CA IX } & Neg & $10(24)$ & $4(20)$ & $1(4)$ & 0.3 \\
\hline & + & $0(0)$ & $0(0)$ & $0(0)$ & \\
\hline & ++ & $1(2)$ & $2(10)$ & $2(9)$ & \\
\hline & +++ & $30(73)$ & $14(70)$ & $20(87)$ & \\
\hline \multirow[t]{4}{*}{ GLUT1 } & Neg & $0(0)$ & $1(5)$ & $0(0)$ & 0.02 \\
\hline & + & $8(20)$ & $6(30)$ & $0(0)$ & \\
\hline & ++ & $15(37)$ & $4(20)$ & $6(26)$ & \\
\hline & +++ & $18(44)$ & $9(45)$ & $17(74)$ & \\
\hline \multirow[t]{4}{*}{ SDF1 } & Neg & $8(20)^{a}$ & $7(37)^{a}$ & $0(0)$ & $<0.005$ \\
\hline & + & $4(10)$ & $4(21)$ & $0(0)$ & \\
\hline & ++ & $13(33)$ & $2(11)$ & $5(22)$ & \\
\hline & +++ & $15(38)$ & $6(32)$ & $18(78)$ & \\
\hline
\end{tabular}

role in the induction of HIF-1 $\alpha$ in normal colorectal mucosa, we used mice that were injected with pimonidazole, a chemical marker of hypoxia that can be visualized by immunohistochemistry. The presence of tissue hypoxia was demonstrated in the surface epithelium of normal colon mucosa of the treated mice (Fig. 3). The pattern of hypoxic cells in the normal colorectal mucosa in mice matched with the distribution of HIF- $1 \alpha$ immunohistochemical staining in human colorectal mucosa.

The presence of HIF- $1 \alpha$ in normal colorectal mucosa was compared with that in adenomas and carcinomas. Adenomas displayed HIF- $1 \alpha$ expression in 53 of the 61 cases, predominantly at the surface, gradually decreasing towards the center of the adenomas. No differences were seen between nonprogressed and progressed adenomas ( $85 \%$ and $90 \%$, respectively), as shown in Table 2 . Of the carcinomas, $78 \%(n=18)$ were positive, showing nuclear staining of HIF- $1 \alpha$ in epithelial tumor cells. In carcinomas, a decreasing gradient of HIF- $1 \alpha$ staining was observed from necrotic areas towards the well-vascularized stroma. Besides the epithelial tumor cells, in carcinomas, inflammatory cells in the tumor-associated stroma, and in five cases B-cells in lymph follicles, were positive for HIF- $1 \alpha$. Statistical analysis showed no significant differences in intensity of HIF- $1 \alpha$ staining between normal mucosa, adenomas, and carcinomas.

VHL, the regulator of HIF- $1 \alpha$ degradation, was also analyzed by means of immunohistochemistry (Fig. 2). VHL expression was observed in all epithelial cells in normal colorectal mucosa as well as in colorectal adenomas and carcinomas.

AKT and mTOR, oncogenic pathways regulating HIF- $1 \alpha$

To investigate whether, in addition to hypoxia, oncogenes and/or growth factors can contribute to the elevated HIF$1 \alpha$, we studied the presence of phosphorylated forms of AKT and mTOR, which reflect an active state of the oncogene-driven pathway of HIF- $1 \alpha$ activation. Lowintensity cytoplasmic staining for the active form of AKT (P-AKT) was seen in epithelial cells of normal mucosa in all tissues (Fig. 4). Positive staining was also seen in the smooth muscle cells of the muscularis propria and muscularis mucosae and in the walls of blood vessels. In 
Fig. 2 Serial sections of normal colon mucosa, colorectal adeno$\mathrm{ma}$, and adenocarcinoma analyzed for HIF-1 $\alpha$ and VHL expression. HIF- $1 \alpha$ staining was observed in the nuclei of surface epithelium of normal mucosa and colorectal adenoma, whereas in adenocarcinomas HIF- $1 \alpha$ was present near hypoxic regions with necrosis. VHL expression was observed in the cytoplasma of all epithelial cells of normal mucosa, adenomas, and adenocarcinomas
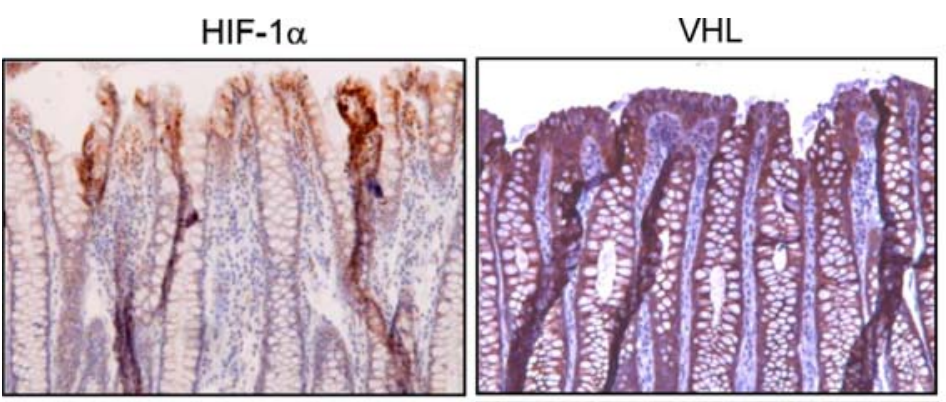

Normal colon tissue
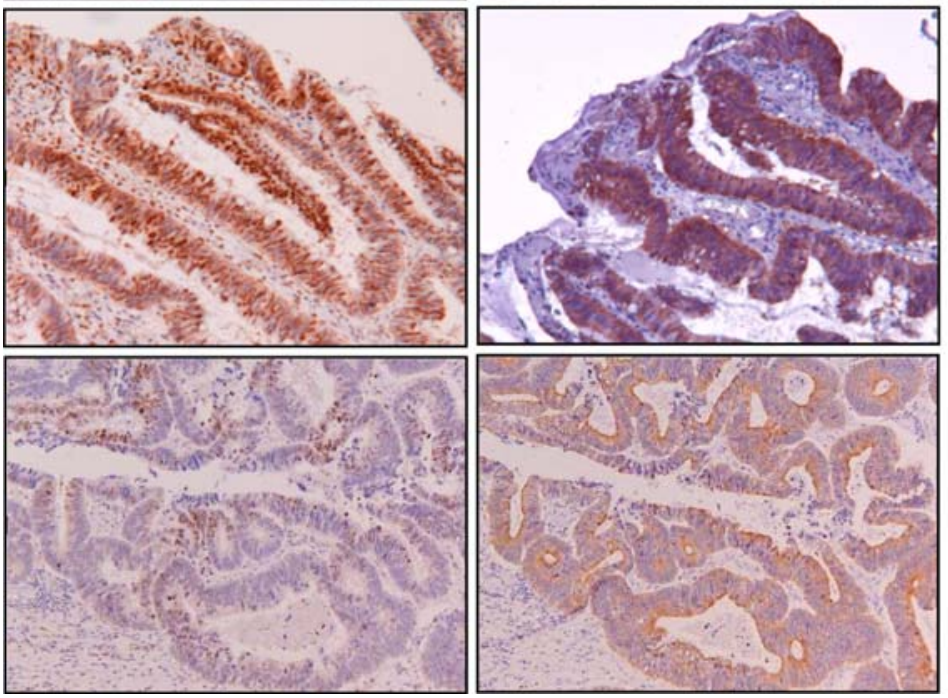

Colorectal adenoma

Colorectal carcinoma adenomas, staining in epithelial cells was more intense, present throughout the neoplastic tissue, and observed in all cases. Staining patterns in adenocarcinomas were similar and also observed in all samples analyzed.

Active mTOR was only present as a cytoplasmatic staining; nuclear staining was not observed in any of the cases (Fig. 4). In normal mucosa, mTOR was detected in the surface epithelium in all tissues. Likewise, in adenoma samples, mTOR was expressed in the surface epithelium but also more diffusely throughout the adenomas. In adenocarcinomas, staining patterns were diffused across the whole tumor, but more intense expression was detected in areas surrounding necrosis. Higher levels of active
mTOR were observed at the invasive front of the tumor. In the adenocarcinomas, besides the cytoplasmic staining in some cells, a clear cellular membrane staining was observed. In all normal mucosa samples, adenomas, and carcinomas, mTOR was present, except for $5 \%$ of the nonprogressed adenomas, which were negative for mTOR (Table 2).

Expression of the HIF1 downstream targets Glut1 and SDF-1

To investigate to what extent downstream pathways were affected by HIF-1 upregulation, several HIF-1 target genes,
Fig. 3 Detection of hypoxia in murine colorectal mucosa by pimonidazole. a Colorectal mucosa of a non-injected mouse, b colorectal mucosa of a mouse that was injected intravenously with pimonidazole. After $90 \mathrm{~min}$, the mouse was killed and colon tissue harvested and formalin fixed. Immunohistochemical staining against pimonidazole revealed hypoxia in the surface epithelium of the normal colon mucosa
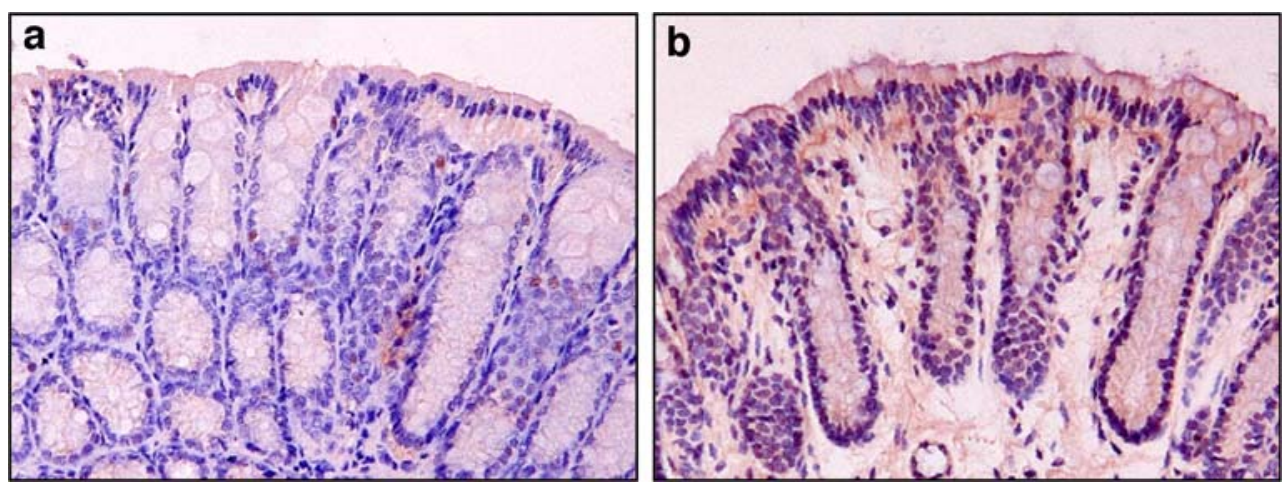
Fig. 4 Typical immunohistochemical staining patterns of the active forms of AKT $(P-$ $A K T)$ and mTOR $(P-m T O R)$ in normal colon mucosa, colorectal adenoma, and adenocarcinomas. Presence of active AKT is seen in the cytoplasm of all epithelial cells with increasing intensities from the normal mucosa towards adenocarcinoma. Presence of active mTOR is restricted to the surface epithelium in normal mucosa and adenomas. In adenocarcinomas, cells surrounding necrotic areas show active mTOR as well. In addition, in adenocarcinomas, intracellular localization of mTOR changes from cytoplasm towards cellular membrane staining
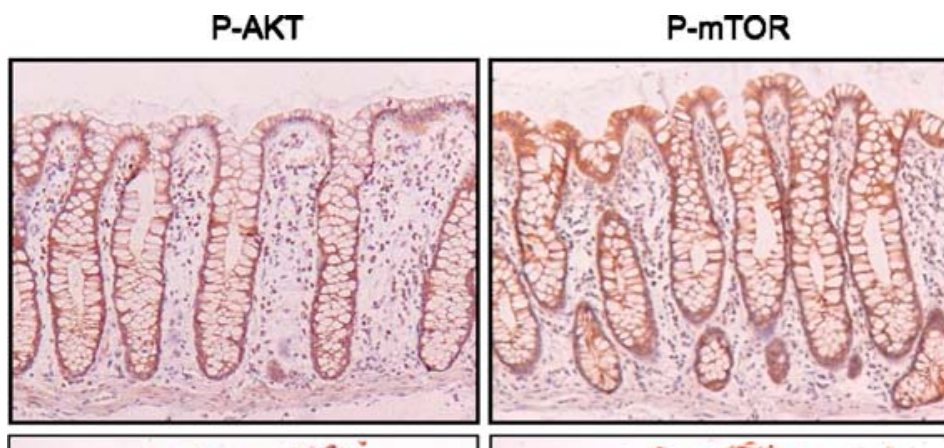

Normal colon tissue
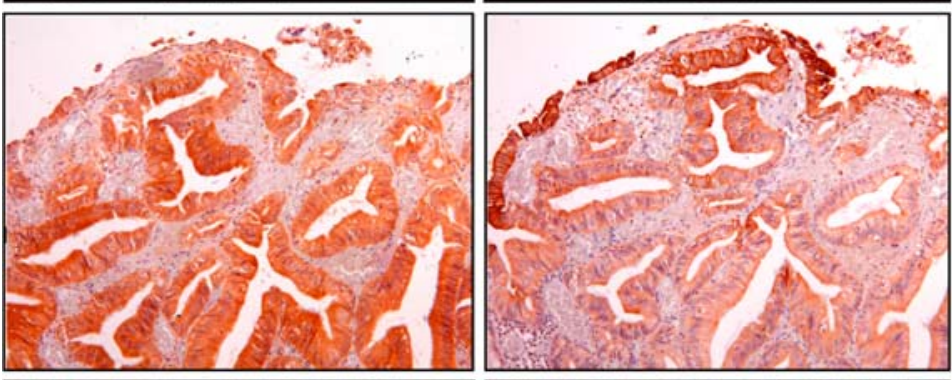

Colorectal adenoma
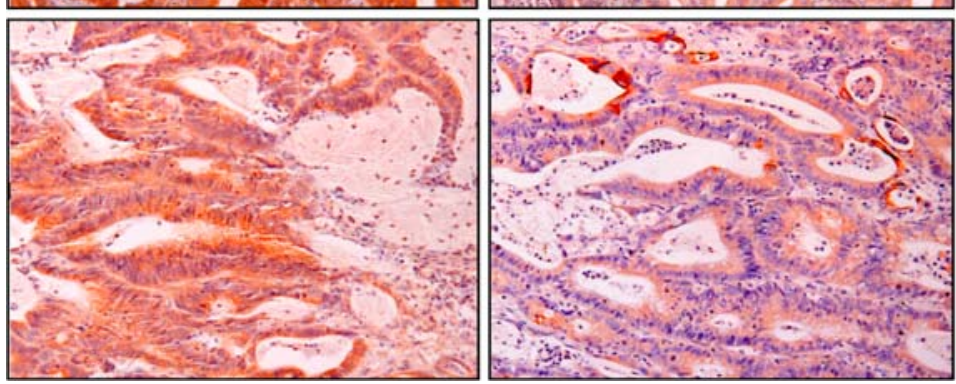

Colorectal carcinoma including GLUT1 and SDF-1, were analyzed in normal mucosa, adenomas, and adenocarcinomas. Expression of GLUT1, which is involved in glucose metabolism, was closely correlated with HIF-1 $\alpha$ in all colon tissues analyzed. In normal colon mucosa, GLUT1 expression showed a gradient from the surface epithelium towards the basis of the crypts (Fig. 5). All normal tissues showed a positive GLUT1 staining. In nonprogressed adenomas, all cases showed GLUT1 expression compared to $95 \%$ of progressed adenomas. All adenocarcinomas $(n=23)$ were positive for GLUT1 as well. Staining was localized at the cell membrane of epithelial cells in normal mucosa, adenomas, and adenocarcinomas (Fig. 5). Most intense staining was seen at the surface epithelium of adenomas and in the vicinity of necrosis in carcinomas. As to staining intensity, a significant difference was detected between the adenomas and the carcinomas (Table 2).

In normal colon tissue, SDF-1 expression was comparable to that of HIF- $1 \alpha$, i.e., it was detected in a gradient from the surface epithelium towards the basis of the crypts. However, in all colorectal adenomas and adenocarcinomas, intense SDF-1 expression was observed in the epithelial cells, which was located in the cell membrane and cytoplasm (Fig. 5). Because this epithelial SDF-1 expression was seen in all epithelial cells, it co-localized only partly with HIF- $1 \alpha$ presence. In contrast to the comparable intensity of the HIF- $1 \alpha$ staining in adenomas and adenocarcinomas, the SDF-1 staining intensity was much higher in adenocarcinomas than in the adenomas (Table 2). In addition to the epithelial expression of SDF-1, endothelial cells of blood vessels stained positive for SDF-1 (Fig. 6).

\section{Expression of CA IX}

CA IX was originally identified in gastrointestinal tissues and later recognized as a HIF-1 target gene in many tissues. In normal mucosa, the presence of CA IX actually did not co-localize with that of HIF- $1 \alpha$. CA IX was observed in the bottom parts of the crypts, i.e., in the proliferative compartment, in contrast to HIF-1 $\alpha$, which was present in the surface epithelium. Seventy percent of the normal tissues showed CA IX expression. In adenomas and particular adenocarcinomas, CA IX and HIF-1 expressions had more resemblance. In adenomas, CA IX was present in a more diffuse pattern throughout the whole adenoma, including the surface epithelium (Fig. 5). In the adenocarcinomas, CA IX showed a perinecrotic staining, mainly co-localizing with the HIF- $1 \alpha$ expression. 
Fig. 5 Typical immunohistochemical staining patterns of HIF-1 $\alpha$, GLUT1, SDF-1, and CA IX in normal colon mucosa, colorectal adenomas, and adenocarcinomas. The downstream targets of HIF-1, i.e., SDF-1, GLUT1, and CA IX, have predominantly overlapping staining with the presence of HIF-1. However, in normal mucosa, CA IX is not expressed in the HIF- $1 \alpha$ positive surface epithelium but is expressed in the basal of the crypts. In adenocarcinomas, SDF-1 is not only present in HIF- $1 \alpha$-positive cells but in all epithelial cells
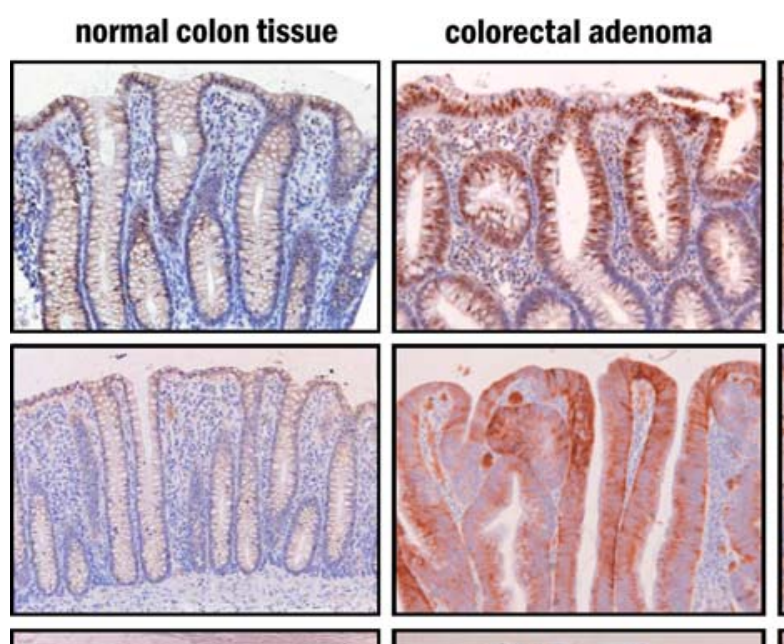

\section{colorectal carcinoma}

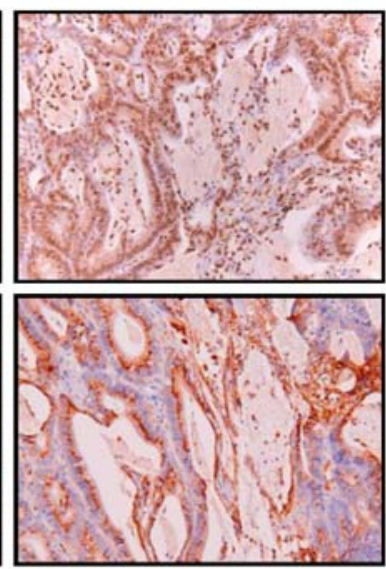

HIF- $1 \propto$

GLUT 1
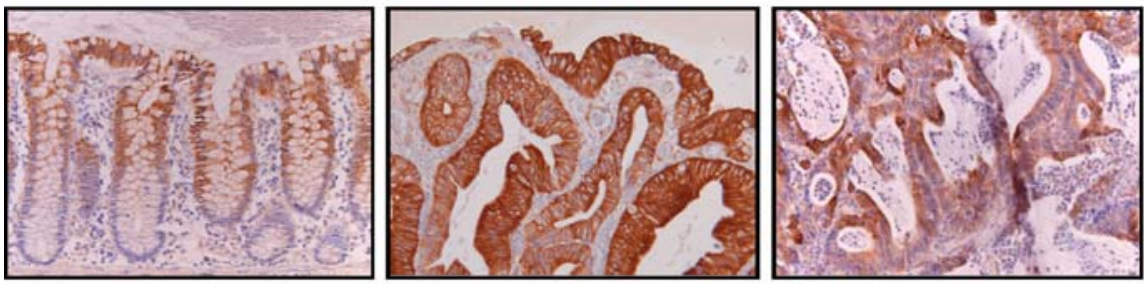

SDF- 1
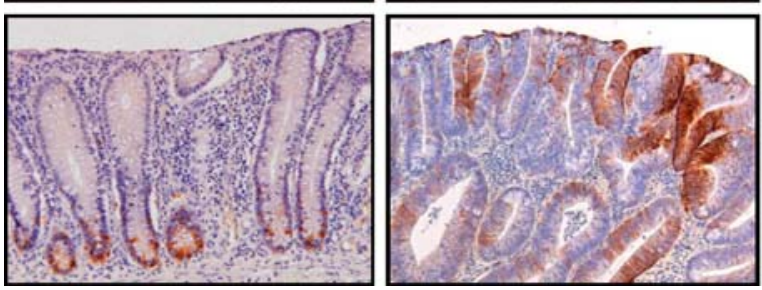

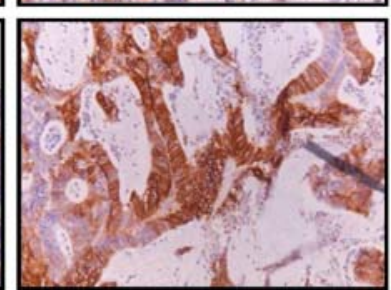

\section{Discussion}

The present study demonstrates the presence of nuclear HIF- $1 \alpha$ in the surface epithelium of normal colon and adenomas and in areas associated with peri-necrotic areas of colon adenocarcinoma. The data support a hypoxiainduced HIF-1 cascade, both in normal and neoplastic colorectal mucosa, as suggested by pimonidazole and HIF$1 \alpha$ patterns in association with GLUT1 and SDF-1 in normal colorectal mucosa and adenomas, as well as perinecrotic HIF- $1 \alpha$ and CA IX patterns in colorectal carcinomas. The occurrence of hypoxia around the surface epithelium was confirmed by pimonidazole staining of unaffected murine colon. Furthermore, hypoxia and the oncogenic activation of the AKT-mTOR pathway both contributed to HIF-1 expression in adenomas and adenocarcinomas. Moreover, the expression patterns of CA IX in normal mucosa and SDF-1 in neoplastic mucosa pointed to additional regulations independent from HIF-1.

The hypoxia-HIF-1 cascade

The presence of HIF- $1 \alpha$ under physiological circumstances in the surface epithelium of normal colorectal mucosa observed in the present study may be due to the anaerobic environment in the lumen of the colon, which contributes to a relatively hypoxic state of especially this surface epithelium. Indeed, we observed accumulation of the chemical hypoxia marker pimonidazole particularly in the

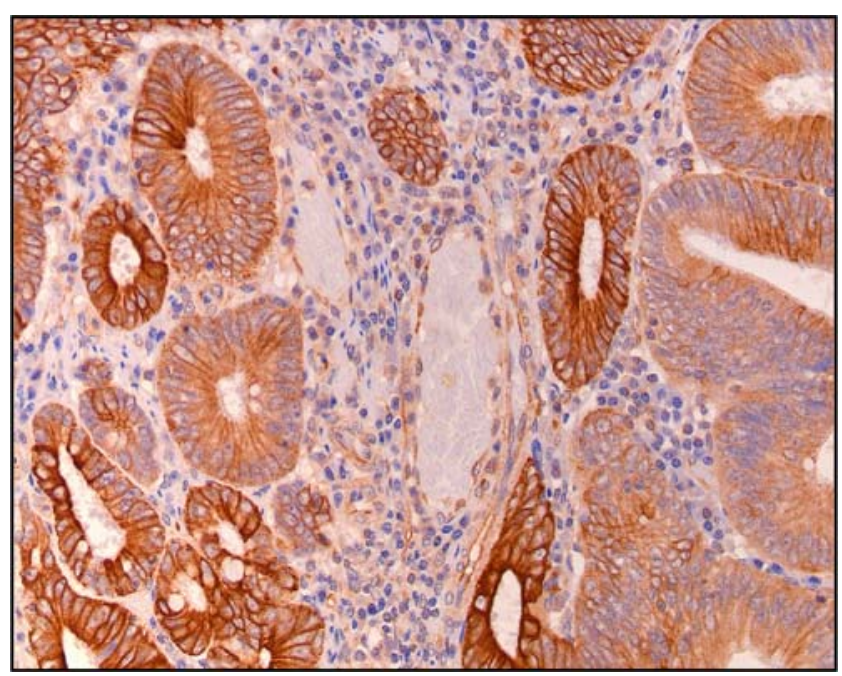

Fig. 6 SDF-1 expression in epithelial and endothelial cells of normal detected by immunohistochemistry 
surface epithelium, indicating low oxygen levels [19]. The presence of pimonidazole showed a gradient towards the basis of the crypts, suggesting that the cause of hypoxia was indeed related to the anaerobic lumen. Apparently, the capillaries in the surface regions of the colon epithelium were unable to cope with the high oxygen demand of the tissue. This strongly suggests that these hypoxic areas may induce HIF- $1 \alpha$, which contributes to a sustained pressure on the stimulation of angiogenesis and glycolysis to adjust the energy levels of these cells.

Although immunohistochemical analysis of patient samples does not allow a formal analysis of functional relationships, it is highly likely that the HIF-1 detected in normal colorectal mucosa was transcriptionally active because HIF-1 $\alpha$ was detected in the nuclei and the HIF-1 downstream targets GLUT1 and SDF-1 were present in the same regions where HIF- $1 \alpha$ was found.

In $87 \%$ of colorectal adenomas, HIF- $1 \alpha$ was present, showing staining predominantly in the nuclei of the surface epithelium. In colorectal adenocarcinomas, the presence of HIF- $1 \alpha$ changes from the surface epithelium to epithelium cells surrounding regions of necrosis, indicating severe hypoxia. Presence of HIF- $1 \alpha$ in the nuclei of epithelial cells went along with expression of the downstream targets GLUT1 and SDF1 in all different stages of the colon carcinogenesis.

In contrast to SDF-1 and GLUT1, the downstream target CA IX, known as a stringent hypoxia marker [35], did not co-localize with HIF-1 $\alpha$ staining in normal colorectal mucosa. It should be noted that CA IX was originally described to have a role in maintaining the physiological equilibrium in the gastrointestinal tract. In fact, CA IX was more abundant in the basal half of the crypts, containing the proliferating compartment, rather than in the upper half of the mucosa where HIF- $1 \alpha$ expression was observed. Indeed, co-localization of CA IX with $\mathrm{Ki}-67$, a proliferation marker, has been found in colorectal cancer [31]. The lack of HIF- $1 \alpha$ in the CA IX-positive regions indicates an HIF$1 \alpha$-independent regulation of CA IX in normal colon epithelium. CA IX expression was reported to be also regulated by the transcription factor SP1 [18, 31].

\section{Oncogenic upregulation of HIF-1}

Oncogene-dependent regulation of HIF-1 can be mediated by the AKT-mTOR pathway $[24,39]$. In the present study, in epithelium of all normal colorectal mucosa, a weak staining of P-AKT was observed, confirming data of Itoh et al. [14]. In all adenomas and adenocarcinomas analyzed, the active (phosphorylated) forms of AKT and mTOR were detected as well. Especially active mTOR showed colocalization with HIF- $1 \alpha$ in normal tissue as well as in adenomas and adenocarcinomas. Co-localization of P-AKT with HIF-1 $\alpha$ was less evident. Recently, in breast cancer, it has been shown that in the absence of P-AKT, only low levels of HIF- $1 \alpha$ could be detected while in the presence of P-AKT high HIF-1 $\alpha$ protein levels were observed [10]. In colorectal tumorigenesis, this regulation mechanism may be less relevant because staining was already observed in normal tissue. In addition, the presence of active AKT was not HIF-1 related because in adenocarcinomas P-AKT was present in a higher percentage of cells present than HIF- $1 \alpha$. The downstream target of AKT, mTOR, displayed comparable cellular expression patterns to HIF- $1 \alpha$ in normal, adenomas, and carcinomas. This suggests that the AKTmTOR-HIF- $1 \alpha$ axis may be important in tumor growth and development as was seen in prostate epithelial cells [25].

\section{Expression of VHL}

An alternative mechanism that can lead to HIF-1 $\alpha$ overexpression is loss of VHL expression. In normal colon mucosa, VHL is expressed, while in colorectal tumors VHL has been found to be lost or mutated in $11 \%$ of cases [7, 21]. Mutations in the VHL gene have been reported to result in cytoplasmic staining of HIF- $1 \alpha$ in colorectal cancer in one study [22], while this could not be confirmed in another study of 80 patients [40]. Also in the present study, no cytoplasmic staining of HIF-1 $\alpha$ was seen at all, and VHL expression was seen in all epithelial cells of normal mucosa, colorectal adenomas, and carcinoma.

\section{Expression of SDF1}

SDF-1 was investigated in the present study as a downstream target of HIF-1 [13, 32]. Surprisingly, epithelial cells showed much stronger SDF-1 expression than endothelial cells lining blood vessels. In addition, expression was not merely restricted to areas showing HIF- $1 \alpha$ staining but was observed in all epithelial adenomas and adenocarcinomas. SDF-1 staining in tumors cells has also been reported in breast cancer patients [29] and in clear cell-renal cell carcinomas, in which HIF- $1 \alpha$ is constitutively expressed [37]. The intense staining of the colon tumor cells suggests that SDF-1 not only has a function in attracting circulating progenitor cells towards the angiogenic areas [12]. Indeed, SDF-1 stimulates intestinal epithelial cell migration and enhances the integrity of the mucosal barrier [34].

The level of expression of SDF-1 might also play a role in tumorigenesis because it is related with prognosis in colorectal cancer. The presence of its coding mRNA and the mRNA of its receptor, CXCR4, have been shown to be a poor prognostic factor [20]. In tumor formation, SDF-1 may bear impact on the recruitment of various types of progenitor cells needed for enhanced growth of the tumor tissue [29]. Our study supports a role of SDF-1 in 
carcinogenesis because SDF-1 staining becomes more intense with the progression of normal colon tissue toward carcinomas. However, future studies are needed to substantiate such role.

\section{Conclusion}

The common expression of HIF-1 $\alpha$ in the surface epithelium of the colorectal mucosa suggests that HIF-1 may play a role in the physiology of normal colon tissue. HIF-1 $\alpha$ presence does not appear to be related to progression of colorectal carcinogenesis in contrast to GLUT1 and SDF-1, which are expressed more intensely at later stages of this process.

Acknowledgements The authors thank Cristel Snijckers and Helma van den Berg for technical assistance and Prof. A.L. Harris for providing the CA IX antibody. This work was supported in part by the 1st AEGON International Scholarship in Oncology.

Conflict of interest statement We declare that we have no conflict of interest.

Open Access This article is distributed under the terms of the Creative Commons Attribution Noncommercial License which permits any noncommercial use, distribution, and reproduction in any medium, provided the original author(s) and source are credited.

\section{References}

1. Airley RE, Loncaster J, Raleigh JA, Harris AL, Davidson SE, Hunter RD, West CM, Stratford IJ (2003) GLUT-1 and CAIX as intrinsic markers of hypoxia in carcinoma of the cervix: relationship to pimonidazole binding. Int J Cancer 104:85-91

2. Aoki K, Tamai Y, Horiike S, Oshima M, Taketo MM (2003) Colonic polyposis caused by mTOR-mediated chromosomal instability in $\mathrm{Apc}+/$ Delta716 $\mathrm{Cdx} 2+/-$ compound mutant mice. Nat Genet 35:13-330

3. Bos R, Zhong H, Hanrahan CF, Mommers EC, Semenza GL, Pinedo HM, Abeloff MD, Simons JW, van Diest PJ, van Der Wall E (2001) Levels of hypoxia-inducible factor-1 alpha during breast carcinogenesis. J Natl Cancer Inst 93:309-314

4. Bos R, Van Der Groep P, Greijer AE, Shvarts A, Meijer S, Pinedo HM, Semenza GL, van Diest PJ, van Der Wall E (2003) Levels of hypoxia-inducible factor-1 alpha independently predict prognosis in patients with lymph node negative breast carcinoma. Cancer 97:1573-1581

5. Ceradini DJ, Kulkarni AR, Callaghan MJ, Tepper OM, Bastidas N, Kleinman ME, Capla JM, Galiano RD, Levine JP, Gurtner GC (2004) Progenitor cell trafficking is regulated by hypoxic gradients through HIF-1 induction of SDF-1. Nat Med 10:858864

6. Cleven AH, Van Engeland M, Wouters BG, de Bruine AP (2007) Stromal expression of hypoxia regulated proteins is an adverse prognostic factor in colorectal carcinomas. Cell Oncol 29:229240

7. Giles RH, Lolkema MP, Snijckers CM, Belderbos M, Van Der Groep P, Mans DA, van Beest M, van Noort M, Goldschmeding R, van Diest PJ, Clevers H, Voest EE (2006) Interplay between VHL/ HIF1alpha and Wnt/beta-catenin pathways during colorectal tumorigenesis. Oncogene 25(21):3065-3070

8. Gingras AC, Raught B, Sonenberg N (2001) Regulation of translation initiation by FRAP/mTOR. Genes Dev 15:807-826

9. Goethals L, Debucquoy A, Perneel C, Geboes K, Ectors N, De Schutter H, Penninckx F, McBride WH, Begg AC, Haustermans KM (2006) Hypoxia in human colorectal adenocarcinoma: comparison between extrinsic and potential intrinsic hypoxia markers. Int J Radiat Oncol Biol Phys 65:246-254

10. Gort EH, Groot AJ, Derks van de Ven TL, Van Der Groep P, Verlaan I, van Laar T, van Diest PJ, van Der Wall E, Shvarts A (2006) Hypoxia-inducible factor-1alpha expression requires PI 3kinase activity and correlates with Akt1 phosphorylation in invasive breast carcinomas. Oncogene 25(45):6123-6127

11. Greijer A, Van Der Groep P, Kemming D, Shvarts A, Semenza G, Meijer G, Van De Wiel M, Belien J, van Diest P, van Der Wall E (2005) Up-regulation of gene expression by hypoxia is mediated predominantly by hypoxia-inducible factor 1 (HIF-1). J Pathol 206(3):391-304

12. Grunewald M, Avraham I, Dor Y, Bachar-Lustig E, Itin A, Yung S, Chimenti S, Landsman L, Abramovitch R, Keshet E (2006) VEGF-induced adult neovascularization: recruitment, retention, and role of accessory cells. Cell 124:175-189

13. Heidemann J, Ogawa H, Rafiee P, Lugering N, Maaser C, Domschke W, Binion DG, Dwinell MB (2004) Mucosal angiogenesis regulation by CXCR4 and its ligand CXCL12 expressed by human intestinal microvascular endothelial cells. Am J Physiol Gastrointest Liver Physiol 286:G1059-G1068

14. Itoh $N$, Semba $S$, Ito $M$, Takeda $H$, Kawata $S$, Yamakawa $M$ (2002) Phosphorylation of Akt/PKB is required for suppression of cancer cell apoptosis and tumor progression in human colorectal carcinoma. Cancer 94:3127-3134

15. Ivan M, Kondo K, Yang H, Kim W, Valiando J, Ohh M, Salic A, Asara JM, Lane WS, Kaelin WG Jr (2001) HIFalpha targeted for VHL-mediated destruction by proline hydroxylation: implications for O2 sensing. Science 292:464-468

16. Jaakkola P, Mole DR, Tian YM, Wilson MI, Gielbert J, Gaskell SJ, Kriegsheim A, Hebestreit HF, Mukherji M, Schofield CJ, Maxwell PH, Pugh CW, Ratcliffe PJ (2001) Targeting of HIFalpha to the von Hippel-Lindau ubiquitylation complex by O2regulated prolyl hydroxylation. Science 292:468-472

17. Kaanders JH, Wijffels KI, Marres HA, Ljungkvist AS, Pop LA, van den Hoogen FJ, de Wilde PC, Bussink J, Raleigh JA, van der Kogel AJ (2002) Pimonidazole binding and tumor vascularity predict for treatment outcome in head and neck cancer. Cancer Res 62:7066-7074

18. Kaluz S, Kaluzova M, Stanbridge EJ (2003) Expression of the hypoxia marker carbonic anhydrase IX is critically dependent on SP1 activity. Identification of a novel type of hypoxia- responsive enhancer. Cancer Res 63:917-922

19. Karhausen J, Furuta GT, Tomaszewski JE, Johnson RS, Colgan SP, Haase VH (2004) Epithelial hypoxia-inducible factor-1 is protective in murine experimental colitis. J Clin Invest 114:10981106

20. Kim J, Takeuchi H, Lam ST, Turner RR, Wang HJ, Kuo C, Foshag L, Bilchik AJ, Hoon DS (2005) Chemokine receptor CXCR4 expression in colorectal cancer patients increases the risk for recurrence and for poor survival. J Clin Oncol 23:27442753

21. Kuwai T, Kitadai Y, Tanaka S, Onogawa S, Matsutani N, Kaio E, Ito M, Chayama K (2003) Expression of hypoxia-inducible factorlalpha is associated with tumor vascularization in human colorectal carcinoma. Int J Cancer 105:176-181

22. Kuwai T, Kitadai Y, Tanaka S, Hiyama T, Tanimoto K, Chayama K (2004) Mutation of the von Hippel-Lindau (VHL) gene in human 
colorectal carcinoma: association with cytoplasmic accumulation of hypoxia-inducible factor (HIF)-1alpha. Cancer Sci 95:149-153

23. Lal A, Peters H, St Croix B, Haroon ZA, Dewhirst MW, Strausberg RL, Kaanders JH, Der Kogel AJ, Riggins GJ (2001) Transcriptional response to hypoxia in human tumors. J Natl Cancer Inst 93:1337-1343

24. Laughner E, Taghavi P, Chiles K, Mahon PC, Semenza GL (2001) Her2 (neu) signaling increases the rate of hypoxia-inducible factor 1alpha (hif-1alpha) synthesis: novel mechanism for hif-1-mediated vascular endothelial growth factor expression. Mol Cell Biol 21:3995-4004

25. Majumder PK, Sellers WR (2005) Akt-regulated pathways in prostate cancer. Oncogene 24:7465-7474

26. Manalo DJ, Rowan A, Lavoie T, Natarajan L, Kelly BD, Ye SQ, Garcia JG, Semenza GL (2005) Transcriptional regulation of vascular endothelial cell responses to hypoxia by HIF-1. Blood 105:659-669

27. Maxwell PH, Wiesener MS, Chang GW, Clifford SC, Vaux EC, Cockman ME, Wykoff CC, Pugh CW, Maher ER, Ratcliffe PJ (1999) The tumour suppressor protein VHL targets hypoxiainducible factors for oxygen-dependent proteolysis. Nature 399:271-275

28. Olive PL, Aquino-Parsons C, MacPhail SH, Liao SY, Raleigh JA, Lerman MI, Stanbridge EJ (2001) Carbonic anhydrase 9 as an endogenous marker for hypoxic cells in cervical cancer. Cancer Res 61:8924-8929

29. Orimo A, Gupta PB, Sgroi DC, Arenzana-Seisdedos F, Delaunay T, Naeem R, Carey VJ, Richardson AL, Weinberg RA (2005) Stromal fibroblasts present in invasive human breast carcinomas promote tumor growth and angiogenesis through elevated SDF-1/ CXCL12 secretion. Cell 121:335-348

30. Roy HK, Olusola BF, Clemens DL, Karolski WJ, Ratashak A, Lynch HT, Smyrk TC (2002) AKT proto-oncogene overexpression is an early event during sporadic colon carcinogenesis. Carcinogenesis 23:201-205

31. Saarnio J, Parkkila S, Parkkila AK, Haukipuro K, Pastorekova S, Pastorek J, Kairaluoma MI, Karttunen TJ (1998) Immunohistochemical study of colorectal tumors for expression of a novel transmembrane carbonic anhydrase, MN/CA IX, with potential value as a marker of cell proliferation. Am J Pathol 153:279-285
32. Schrader AJ, Lechner O, Templin M, Dittmar KE, Machtens S, Mengel M, Probst-Kepper M, Franzke A, Wollensak T, Gatzlaff P, Atzpodien J, Buer J, Lauber J (2002) CXCR4/CXCL12 expression and signalling in kidney cancer. Br J Cancer 86:1250-1256

33. Semenza GL (2003) Targeting HIF-1 for cancer therapy. Nat Rev Cancer 3:721-732

34. Smith JM, Johanesen PA, Wendt MK, Binion DG, Dwinell MB (2005) CXCL12 activation of CXCR4 regulates mucosal host defense through stimulation of epithelial cell migration and promotion of intestinal barrier integrity. Am J Physiol Gastrointest Liver Physiol 288:G316-G326

35. Wykoff CC, Beasley NJ, Watson PH, Turner KJ, Pastorek J, Sibtain A, Wilson GD, Turley H, Talks KL, Maxwell PH, Pugh CW, Ratcliffe PJ, Harris AL (2000) Hypoxia-inducible expression of tumor-associated carbonic anhydrases. Cancer Res 60:7075-7083

36. Yoshimura H, Dhar DK, Kohno H, Kubota H, Fujii T, Ueda S, Kinugasa S, Tachibana M, Nagasue N (2004) Prognostic impact of hypoxia-inducible factors 1 alpha and 2alpha in colorectal cancer patients: correlation with tumor angiogenesis and cyclooxygenase2 expression. Clin Cancer Res 10:8554-8560

37. Zagzag D, Krishnamachary B, Yee H, Okuyama H, Chiriboga L, Ali MA, Melamed J, Semenza GL (2005) Stromal cell-derived factor-1 alpha and CXCR4 expression in hemangioblastoma and clear cell-renal cell carcinoma: von Hippel-Lindau loss-offunction induces expression of a ligand and its receptor. Cancer Res 65:6178-6188

38. Zhong H, De Marzo AM, Laughner E, Lim M, Hilton DA, Zagzag D, Buechler P, Isaacs WB, Semenza GL, Simons JW (1999) Overexpression of hypoxia-inducible factor 1alpha in common human cancers and their metastases. Cancer Res 59:5830-5835

39. Zhong $\mathrm{H}$, Chiles $\mathrm{K}$, Feldser $\mathrm{D}$, Laughner $\mathrm{E}$, Hanrahan $\mathrm{C}$, Georgescu MM, Simons JW, Semenza GL (2000) Modulation of hypoxia-inducible factor 1alpha expression by the epidermal growth factor/phosphatidylinositol 3-kinase/PTEN/AKT/FRAP pathway in human prostate cancer cells: implications for tumor angiogenesis and therapeutics. Cancer Res 60:1541-1545

40. Zhuang Z, Emmert-Buck MR, Roth MJ, Gnarra J, Linehan WM, Liotta LA, Lubensky IA (1996) von Hippel-Lindau disease gene deletion detected in microdissected sporadic human colon carcinoma specimens. Hum Pathol 27:152-156 